\title{
PUBLICACIONES SOBRE SEXUALIDAD EN LA ESPAÑA DEL PRIMER TERCIO DEL SIGLO XX: ENTRE LA MEDICINA Y LA PORNOGRAFÍA ${ }^{1}$
}

por

\author{
RaQuel Álvarez Peláez \\ Instituto de Historia, C.S.I.C., Madrid
}

RESUMEN: En la España de los años veinte y treinta del siglo XX se publicaron un gran número de libros, folletos $y$ artículos en revistas y periódicos sobre el sexo y la sexualidad. Era una verdadera reacción frente a la tensión creada por los cambios que se iban dando en la sociedad y a las rígidas normas morales imperantes. Dentro de esta literatura, habia obras de todo tipo: obras estrictamente médicas, obras de divulgación de los llamados «sexólogos», médicos o no, novelas, etc. Aquí, tratamos de este tipo ambiguo de publicaciones, que en muchos casos bacen dudar sobre su seriedad, aunque estén firmadas por quienes se llaman a sí mismos médicos, publicaciones que en muchos casos caen en el relato pornográfico. Analizamos en este artículo, pues, algunos de los trabajos que pertenecen a esta categoría, si así puede llamársela, una literatura que va desde una apariencia de seria divulgación de los conocimientos sobre la sexualidad hasta la casi abierta pornografía.

Palabras Clave: Divulgación sexual. Eugenesia. Medicina. Moral sexual.

ABSTRACT: In Spain in the 1920s and 1930s a great number of books, pampblets and articles were published in magazines and newspapers about sex and sexuality. This was an important response to the tension created by major changes taking place in Spanish society and in the prevailing rigid moral norms. Within this literature there were works of all types; those strictly medical, works of popularization of the so-called "sexólogos", medical or not, novels, etc. I analyze here this ambiguous type of publications, whose seriousness may be called into question, although those who called themselves doctors signed them. They are publications that fall in the pornographic category in many cases. I analyze in this paper some of the works that belong to this category; a form of literature that spans what might appear to be serious popularization of knowledge about sexuality to almost open pornography.

1 Trabajo realizado dentro del proyecto del MCYT BHA 2002-00588. 
KEY WORDS: Popularization of sexual knowledge. Medicine. Sexual morality.

«Todo lo que intenten los reformadores eugenistas será contrarrestado siempre en los chocolates vespertinos de las clásicas reuniones que convocan los directores de la vida intelectual de esas ciudades, de horizontes naturales limitados no por las sabias barreras de la religión, sino, fatalmente, por los pétreos e indestructibles muros de la iglesia. Pero esto no quiere decir que la atonía sexual sea la consecuencia de esas prohibiciones, lo que resultaría más positivo desde el punto de vista de la higiene de la raza; al contrario, los sentidos todos que determinan la explosión de los instintos actúan de una manera solapada y continua, creando una atmósfera completamente artificial, dentro de la que no dejan de ser posibles todas las satisfacciones más criminales en el terreno en que imperan los diablos rojos del sexo. Esa moral, que imposibilita el tránsito por los caminos naturales, ha de dirigirse siempre por los senderos sinuosos: a la vieja moral le repugnó siempre la noble línea recta» 2 .

Como vemos en estas palabras del sexólogo Martín de Lucenay, la situación con respecto al sexo y la sexualidad, tal como estos conceptos se habían ido construyendo en España a lo largo del siglo XIX, era realmente objeto de una poderosa normalización dirigida, esencialmente, por una Iglesia Católica que era especialmente rígida y reaccionaria con respecto a la moral sexual. Todos los aspectos del comportamiento sexual y de la sexualidad —el papel de la mujer y del hombre, los modelos de virilidad y feminidad, las relaciones entre los sexos, etc. - estaban firme y estrictamente establecidos y, en gran medida, interiorizados por quienes lo soportaban. Cualquier práctica sexual dentro del matrimonio que no fuera el coito realizado de forma «ortodoxa» podía ser considerada como una perversión, no digamos pues las relaciones fuera del matrimonio o entre personas del mismo sexo. Recordemos que estaba prohibido por la Iglesia incluso el coitus interruptus.

Existe, no obstante, un gran número de obras que han analizado el desarrollo y la construcción de la sexualidad en España, en particular en los años veinte y treinta del siglo $\mathrm{XX}^{3}$. Se trataba de una verdadera reacción frente a la ten-

2 Martín de Lucenay, A.: La selección sexual, Madrid, Editorial Fénix (Temas sexuales, 20), 1933, pp 89-90.

3 Citemos, por ejemplo, a AZA, Vital: Feminismo y sexo, Madrid, Morata, 1928; BARCIA GoYANES, Juan José: La vida, el sexo y la herencia, Madrid, Morata, 1928; CAMPOY IBÁÑEZ, Antonio: El amor y la patología, Prólogo de G. Marañón, Madrid, Morata, 1931; Díez FernÁNDEZ, Dr. Carlos: Castidad, Impulso, Deseo, Madrid, Morata (Nueva Generación), 1930; Hernández Alfonso, L.: Eugenesia y derecho a vivir, Madrid, Morata, 1933; LAFORA, Gonzalo R. y COMAS, Margarita: La educación sexual y la coeducación de los sexos, Buenos Aires, Losada, 1947 (1 $1^{\text {a }}$ ed., 1930); MONTERO GutiÉrREZ, Eloy: Neomaltusianismo, eugenesia y divorcio, Prólogo de Ramiro de Maeztu, Madrid, 1932; RUIZ FUNES, M.: Endocrinología y criminalidad, Madrid, Morata, 1929; SALDAN̄A, Quintiliano: La sexología (Ensayos) I. Qué es la sexología, II. La vida de los sexos; III. Psicología de la vida sexual; IV. La

Hispania, LXIV/3, núm. 218 (2004) 947-960 
sión creada por los cambios que se iban dando en la sociedad y a las rígidas normas morales imperantes. Dentro de esta literatura, había obras de todo tipo: obras estrictamente médicas, obras de divulgación de los llamados «sexólogos», médicos o no, novelas, etc. Trataremos aquí de este tipo ambiguo de publicaciones, que en muchos casos hacen dudar sobre su seriedad, aunque estén firmadas por quienes se llaman a sí mismos médicos, publicaciones que en muchos casos caen en el relato pornográfico.

\section{SEXUALIDAD, MORAL Y MEDICINA}

La progresiva medicalización de la sexualidad, que había comenzado en el siglo XVIII en relación con las medidas de higiene y.prevención y cuyo punto de partida podría situarse con la publicación por Tissot de L'Onanismé, así como la potente penetración de la biología, impulsada en gran medida por el evolucionismo darwinista, permitieron nuevas y «modernas» interpretaciones de lo normal y lo patológico que se reflejan en los escritos y pensamientos de los profesionales españoles. La literatura que se produce a lo largo del primer tercio del siglo $\mathrm{XX}$ resulta por lo tanto muy significativa para valorar la represión y, a la vez, la exaltación producida por las prohibiciones morales y religiosas 5 .

De todos modos, hay que tener en cuenta que todo lo referente al sexo ha sido y será siempre motivo de especial atención desde todos los puntos de vista. Las sociedades han tenido y tienen muchas normas relacionadas con el sexo y la sexualidad, tanto porque es una forma de control de los individuos y de organizarlos como por el importante producto de la relación sexual, los niños, y, en definitiva, la futura población. Pero esos controles y normas tendrán unas características u otras dependiendo de muchos factores, sociales, políticos, económicos, de volumen de población, de condiciones de vida, etc.

En el caso de la España de ese primer tercio del siglo XX, había, por un lado, unas condiciones económicas, una estructura política y una situación social desastrosas, condiciones controladas por una oligarquía arropada por la Iglesia Católica, conformando un bloque dirigente que apoyaba en gran medida su control por medio de la moral religiosa y de los propios sacerdotes como gran policía protectora de las normas.

educación sexual; V. Ética sexual; VI. El celibato eclesiástico; VII. Criminología sexual, Madrid, Mundo Latino, 1930. Ver VázQuez García, Francisco y Moreno Mengíbar, Andrés: Sexo y Razón. Una genealogía de la moral sexual en España (siglos XVI-XX), Madrid, Akal, 1997, 474 p., y AMEZÚA, Efigenio: «Cien años de temática sexual en España: 1850-1950: Repertorio y análisis», Revista de Sexología (Madrid), $\mathrm{n}^{\circ} 48$ (1991).

4 Tissot, Samuel Auguste: L'onanisme, Paris, 1760. Existe una edición reciente en castellano: Tissot, S. A.: El onanismo, Madrid, Asociación Española de Neuropsiquiatras, 2003.

5 MARTínez PÉreZ, José: «Sexualidad y orden social: la visión médica en la España del primer tercio del siglo XIX», Asclepio (Madrid), n 42 (1990), n 2, pp. 119-135. 
Pero, como en toda situación anómala, en que las normas que se imponen o se quieren imponer chocan frontalmente con la propia transformación de la sociedad, se establece, por un lado, una lucha contra esas normas, y por otro, escapatorias que se saltan esas normas y que, además, por la propia prohibición, adquieren un atractivo mayor. En otros trabajos, nos hemos referido, así como otros autores, al enfrentamiento entre gran parte de los intelectuales españoles de los años veinte y treinta del siglo XX con las normas establecidas, defendidas por el Estado y la Iglesia. Luchas en defensa de la mujer y el niño, de la madre soltera y su progenie, del control de natalidad y, sobre todo, de la educación sexual como medio de combatir gran parte de los males de la población de la época: mortalidad infantil y materna, enfermedades venéreas, etc. ${ }^{6}$.

La búsqueda de soluciones, la lucha por la liberación sexual y sus diversos aspectos se canalizó, en España, a través de diversas doctrinas y movimientos que hacían mayor o menor hincapié en algunos de esos componentes. En la zona de Cataluña y Valencia ${ }^{7}$, se desarrollaron en gran medida los movimientos nacidos de la Liga de Regeneración de Paul Robin, con la revista y la editorial Salud y Fuerza, que luchaba fundamentalmente por el control de natalidad, el famoso Birth-control, y el movimiento libertario, que publicaba primero Generación Consciente, nacida en Alcoy, y después Estudios ${ }^{8}$, ya en Valencia en la que, además de tratarse de todo (política, ciencia, etc.), existió un Consultorio Psíquico-sexual conducido por el médico Félix Martí Ibáñez, quien llegó a ser Director General de Sanidad de la Generalitat de Cataluña durante la Guerra Civil, en 1937, durante diez meses.

En ese tiempo, además de sus manifiestos eugénicos a mujeres y obreros y su incansable actividad política y médica, Félix Martí Ibáñez redactó un decreto que permitía el aborto con la única condición de que fuera realizado antes de los tres meses de embarazo, límite que podía salvarse en caso de necesidad de la madre o del feto.

6 Álvarez, Raquel: «Herencia, sexo y eugenesia», en Huertas, R., Romero, I., Álvarez, R.: Perspectivas Psiquiátricas, Madrid, C.S.I.C., 1987, pp 203-218, «La mujer española y el control de natalidad en los comienzos del siglo XX», Asclepio (Madrid), vol. XLII (1990), n² 2, pp. 175-200, y «Medicina y moral sexual en la España de preguerra», Ibid., pp. 201-210; CASTEJÓN BOLEA, Ramón: Moral sexual y enfermedad: La medicina española frente al peligro venéreo (1868-1936), Granada, Universidad de Granada, 2001.

7 Cleminson, Richard: Anarquismo y bomosexualidad. Antología de Artículos de La Revista Blanca, Generación Consciente, Estudios e Iniciales (1924-1935), Madrid, Huerga y Fierro Editores, 1995; NASH, Mary: «La reforma sexual en el anarquismo español», en HofMANN, Bert, I Tous, Pere y TIETZ, Manfred (eds.): El anarquismo español y sus tradiciones culturales, Frankfurt-Madrid, Vervuert-Iberoamericana, 1995, pp 281-296, y Rojas. Las mujeres republicanas en la Guerra Civil, Madrid, Taurus, 1999; ÁLvAREZ, Raquel: «Eugenesia y darwinismo social en el pensamiento anarquista», en HOFMANN, Bert, JOAN I TOUS, Pere y TIETZ, Manfred (eds.): El anarquismo español, op. cit., pp. 29-40.

8 Ver Navarro Navarro, Francisco Javier: «El paraíso de la razón». La revista Estudios (19281937) y el mundo cultural anarquista, Valencia, Ed. Alfons el Magnànim, 1997.

9 MARTí IBÁN̄EZ, Félix: Consultorio psíquico-sexual, Barcelona, Tusquets, 1975. 
Otra de las doctrinas que se utilizaron como apoyo de esa lucha por una mayor libertad sexual fue la eugenesia, que se conoció pronto en España, desde comienzos del siglo XX, pero que tuvo su mayor auge en los años veinte y treinta ${ }^{10}$. Sus propuestas, basadas en la consideración de la importancia de la herencia en la determinación de todo tipo de caracteres, físicos, mentales y morales, tuvo gran importancia porque sus propuestas de control de la procreación fueron admitidas y adaptadas, tanto en el determinismo hereditario como en las formas de control del matrimonio, por las más diversas ideologías, desde las más revolucionarias hasta las de extrema derecha, de lo que existen claros ejemplos en la literatura de todo tipo —-médica, legal, teológica-, en novelas y obras propagandísticas.

\section{LOS LIBROS DE DIVULGACIÓN SEXUAL}

En este caso, vamos a referirnos sin embargo a libros que tenían un sesgo, una vertiente, que quizás podríamos llamar pornográfica, muchas veces ambigua, difícil de clasificar desde luego, pero que, por razón de su presentación, sus ilustraciones o el tono de su contenido, nos indican una intención que va más allá de la reflexión, discusión o información que podríamos llamar seria.

Podríamos decir que existía una serie de libros de especialistas en temas relacionados con la educación sexual, el sexo dentro del matrimonio, el parto, las posibles alteraciones ginecológicas, integrado todo ello dentro de un nivel estrictamente médico aunque fueran obras de divulgación. Así podríamos clasificar a los libros de Francisco Haro, por ejemplo ${ }^{11}$. En otros casos, se manifestaba en los libros la preocupación por la educación sexual, la elección de pareja, las medidas a tomar para el cuidado de los hijos, dentro de los cuales entrarían los libros sobre eugenesia, control de natalidad, etc., como los publicados por Gregorio Marañón ${ }^{12}$, Hil-

10 Álvarez, Raquel: «La eugenesia española a lo largo del siglo XX», en Romeo CaSABOnA, Carlos María (ed.): Eugenesia Hoy, Bilbao-Granada, Publicaciones de la Cátedra Interuniversitaria de Derecho y Genoma Humano-Fundación BBV-Diputación Foral de Bizcaia, 1999, pp. 87-121, y "Origen y desarrollo de la eugenesia en España», en SÁNCHEZ RON, José Manuel (ed.): Ciencia y Sociedad en España, Madrid, Ed. El arquero-C.S.I.C., 1988, pp. 179-204.

11 Haro, Francisco: Eugenesia y matrimonio. El Certificado Médico Prenupcial, Madrid, Morata, 1932.

12 Marañón, Gregorio: Biología y Feminismo, Madrid, Extraído de El Siglo Médico, 1920; «Notas para la biología de Don Juan», Revista de Occidente (Madrid), Enero de 1924; Amor, Conveniencia y Eugenesia, Madrid, Editora Nacional, 1961 ( $1^{\text {a }}$ ed. 1929); La educación sexual y la Diferenciación Sexual. Valencia, Generación Consciente, s.f.; Tres ensayos sobre la vida sexual. Sexo, trabajo y deporte. Maternidad y feminismo. Educación sexual y diferenciación sexual, Santiago de Chile, Editorial Cultura, 1936 ( $1^{a}$ ed. 1926); Sección Innere Sekretion, Comunicación $N^{\circ} 22$, «Innere Sekretion", «Sécrétion interne», "Inner secretion», en Sexualnot und Sexualreform. Verbandlungen der Weltliga für Sexualreform, IV. Kongress, Abgehalten zu Wien vom 16 bis 23 September 1930, Redigiert von Dr. Herbert Steiner, Wien, Elbemühl-Verlag, 1931, pp. 199-222; Los Estados Intersexuales en la Especie Humana, Madrid,

Hispania, LXIV/3, núm. 218 (2004) 947-960 
degart ${ }^{13}$, Luis Huerta ${ }^{14}$, Higinio Noja Ruiz ${ }^{15}$, y muchos más.

Sin embargo, existían obras que, utilizando incluso un abundante aparato médico, dejaban traslucir una actitud más libre y enfrentada con la moral admitida. También, dentro de estas publicaciones, existían grados, siendo algunas más comedidas en sus relatos sexuales y en sus ejemplos gráficos y otras - a veces perteneciendo al mismo autor- abiertamente dedicadas al relato de lo que fundamentalmente eran consideradas como perversiones y aberraciones sexuales. A este tipo de libros nos vamos referir más concretamente en este trabajo ${ }^{16}$.

Nos encontramos, en general, con series o colecciones que abarcan diversos temas referidos a la sexualidad, muchas veces bajo un amplio título como los de Higiene del matrimonio, Guía íntima del matrimonio, Conocimientos para la vida privada, El consejero del matrimonio o, simplemente, Temas sexuales. Estos libros están, en gran parte de los casos, ilustrados con fotografías, dibujos o grabados, que, como es lógico, eran un elemento esencial para la promoción de ese tipo de obras: imágenes de mujeres más o menos desnudas, en muchos casos exóticas - -seguramente era menos peligroso desde el punto de vista de una posible censura- o de actos "perversos», seguramente porque era un elemento importante para la venta de estas obras. Las obras más pequeñas, casi folletos, llevaban en la portada un dibujo en colores de, por ejemplo, una «perversión» (flagelación, relación entre mujeres, etc.).

Las series no eran todas del mismo estilo, ni por su apariencia, ni en el enfoque de los contenidos, ni en la forma de tratar los diversos temas. Algunas de las obras tenían una presentación seria, una portada en absoluto indicativa de su contenido, que algunas veces era más controlado, más médico y científico que el de otras series que no intentaban ni siquiera aparentarlo. En algunos casos, el autor no aparecía citado en la portada, sino en el interior. Y muchas veces se justificaba la publicación acudiendo a frases de revistas médicas extranjeras o de personajes que habían expresado su opinión sobre la necesidad del conocimiento de la sexualidad y por lo tanto de la educación sexual.

En cuanto al contenido de las obras, es también diverso. En algunos casos, las opiniones y análisis se apoyan en referencias de autoridades nacionales o extranjeras que habían tratado el tema de la sexualidad, aparentando realizar

Javier Morata, 1929; "Acerca del problema de la intersexualidad. (Réplica a un artículo del Dr. Oliver Brachfeld)», El Siglo Médico (Madrid), n 4082 (1932), pp 243-247.

13 HildegART: Educación sexual, Madrid, 1931, y Maltbusismo y Neomaltbusismo. El control de natalidad, Madrid, Morata, 1932.

14 Huerta, Luis: Prostitución, abolicionismo y mal venéreo, Valencia, Biblioteca «Orto», 1933, $204 \mathrm{p}$.

15 NoJa RUIZ, Higinio: Notas sobre amor y sexualismo, Valencia, Libre-Studio, 1938.

16 En un trabajo previo, nos hemos referido a las publicaciones de médicos como Marañón o Martí Ibáñez, las que hemos llamado publicaciones «sesudas». Ver ÁlVAREZ, Raquel: «Sexo y perversión en la España de los años veinte», en Actas del XII Congreso de la Sociedad Española de Historia de la Medicina, Albacete, José Martínez Pérez, 2004, pp. 857-878.

Hispania, LXIV/3, núm. 218 (2004) 947-960 
un estudio serio que se intenta divulgar, y realmente demuestran un conocimiento que puede responder a que fueran médicos que habían buscado una vía de mejorar sus ingresos, lo que no es de sorprender pues siempre ha habido formas de atraer o mejorar la clientela proclamando tratar enfermedades secretas, venéreas, etc. Entre las autoridades más citadas, que son muchas, se encuentran Krafft-Ebing, Havelock Ellis, Freud, y Marañón.

En los textos, se hace referencia a la necesidad de la educación sexual, y en algunos casos a la eugenesia en relación con la selección de pareja y al control de natalidad. Desde luego, el control de natalidad fue una medida defendida no originariamente dentro de las proposiciones eugenistas; en algunos casos, se integró a ellas y en otros circuló como una corriente liberadora de la mujer y método para evitar la alta mortalidad infantil sin estar relacionada con la eugenesia sino más bien con el pensamiento anarquista.

Muy posiblemente, y eso no hemos podido aún estudiarlo, estas obras tuvieron amplia difusión y fueron importantes para gente que desconocía muchos de los aspectos de las relaciones sexuales, aunque para otros fuera una cuestión de «regodeo pornográfico». Para que se comprenda mejor el carácter de estas obras y su variedad, daremos algunos ejemplos que creemos significativos de esas diferentes formas de hacer.

\section{LAS «LECCIONES DE SEXOLOGÍA» DE JUSTO Mª ESCALANTE}

Comenzaremos por referirnos a algunos de los libros que podríamos considerar más serios, como los del Dr. Justo $\mathrm{M}^{\mathrm{a}}$ Escalante. Esta obra tiene el formato y la apariencia de muchos de los libros de la época, de un color neutro, letras en negro o rojo y ninguna ilustración en la cubierta. Sin embargo, el título y los subtítulos prometen algo más de lo que ofrecería esa sobriedad externa. Se titula Iniciación en la vida sexual. La moderna educación sexual. Higiene secreta del matrimonio. Virginidad y desfloración ${ }^{17}$.

Son, indudablemente, aspectos de la sexualidad que normalmente cualquier persona, más en aquel período de oscurantismo, estaría interesada en conocer. Para dar más respaldo a su seriedad, bajo el título puede leerse «Lecciones de sexología basadas en los estudios de los doctores Segismundo Freud, Havelock Ellis, Augusto Forel, William Drauger y Gregorio Marañón». Las grandes figuras internacionales parecen avalar, pues, su texto. Texto en el que describe minuciosamente y presenta dibujos de los genitales masculinos y fe-

17 ESCALANTE, Dr. Justo $\mathrm{M}^{\mathrm{a}}$ : Iniciación a la vida sexual. La moderna educación sexual. Higiene secreta del matrimonio. Virginidad y desfloración, Lecciones de sexología basadas en los estudios de los doctores Segismundo Freud, Havelock Ellis, Augusto Forel, William Drauger y Gregorio Marañón, Barcelona, Carlos Ameller, 1933.

Hispania, LXIV/3, núm. 218 (2004) 947-960 
meninos con sus diversos componentes y estructuras, así como dibujos y descripciones del coito como si de un libro de anatomía se tratara.

Todo está expuesto pues en un tono serio y doctoral, pero es indudable que todo ello era, además, muy atrayente para un público ávido de tales ocultos conocimientos. Los sesenta heliograbados que se anuncian al comienzo del libro eran una buena propaganda. El tono de la obra podría corresponder a cualquiera de las obras actuales de divulgación, pero en aquel momento ese tipo de demostración no era aceptable, no debía difundirse entre el público en general y debía estar restringido a los especialistas.

Es la opinión explícita de la Iglesia y de las autoridades cuando se ofrece el Primer Curso Eugénico español, que ni siquiera se refería a esos aspectos concretos $^{18}$. Pero sus conferencias fueron suspendidas porque acudía muchísimo público, lo que provocaba, según el decreto de suspensión, un verdadero «regodeo pornográfico».

En todo caso, el tono doctoral del texto de Escalante se apoya en sesudas citas de Havelock Ellis, Augusto Forel, Magnus Hirschfeld y Gregorio Marañón. En este caso, se sale un poco de la rutina refiriéndose a Magnus Hirschfeld, pues, como se verá, Escalante conocía el movimiento llamado Liga para la Reforma Sexual sobre Bases Científicas ${ }^{19}$.

El detalle de las descripciones y de los grabados podría responder tanto a una obra especializada como a un uso de esos conocimientos para vender mejor la sexualidad. Y eso parece cuando vemos las obras que se anuncian en la contraportada, que le sitúan dentro de las series fuera del circuito «normal» de las obras serias sobre el tema de la sexualidad. Se anuncia, por ejemplo, el libro Satanismo erótico. El amor y la lujuria en los procesos e bistorias de la magia negra y la bechicería, «Compilación sistematizada y glosada por el Dr. Justo María Escalante», además de otras obras de otros autores situados en la misma línea, como Antonio San de Velilla con su Sodoma y Lesbos modernas. Pederastas y safistas, estudiados en la clínica, en los libros y en la bistoria ${ }^{20}$.

Escalante se refiere también a la educación sexual señalando su gran importancia, como, dice, explica ampliamente Havelock Ellis. También introduce el autor una larga cita de Gregorio Marañón sobre el problema de la relación de padres e hijos y la educación sexual, que debería iniciarse, como había señalado Freud, en la infancia, puesto que ya existe en los niños. Como dije antes, Escalante conocía perfectamente la existencia de la Liga Mundial para la Reforma Sexual y el desarrollo de los importantes congresos de 1928 y 1929. Incluso,

18 Noguera, Enrique y Huerta, Luis (eds.), Genética, Eugenesia y Pedagogía sexual. Libro de las primeras jornadas eugénicas españolas, Madrid, Javier Morata, Editor, 1934, 2 t., 450 p. y 412 p.

19 Ver DosE, Ralph: "The World League for Sex Reform: some possible approaches», en EDER, Franz X., HALL, Lesley A., Hekma, Gert (eds.): Sexual Cultures in Europe. National Histories, Manchester, Manchester University Press, 1999, pp. 242-259.

20 San de Velilla, A.: Sodoma y Lesbos modernas. Pederastas y safistas estudiados en la clínica, en los libros y en la bistoria, Barcelona, Ameller, s.f.

Hispania, LXIV/3, núm. 218 (2004) 947-960 
dice que escribió este libro como apoyo a la Liga, que como es bien sabido tuvo su rama española propulsada por Hildegart, propagandista del control de natalidad y de la educación sexual, bien conocida por Ellis y de la que cabe recordar algunos elementos.

En efecto, Hildegart Rodríguez, además de por sus actividades y su precocidad, fue tristemente conocida porque fue asesinada por su madre Aurora Rodríguez, que la había criado según las normas de la eugenesia para convertirla en un genio. Cuando la chica intentó organizar su propia vida -impulsada, en parte, por Havelock Ellis - e independizarse de su madre, ésta la mató ${ }^{21}$. Havelock Ellis, famoso estudioso de la sexualidad, escribió un artículo sobre Hildegart titulado «La Virgen Roja» y, según parece, quería que se convirtiera en su secretaria. La Liga Española para la reforma sexual sobre bases científicas fue presidida al comienzo y por muy poco tiempo por Gregorio Marañón, siendo secretaria Hildegart y teniendo su sede en el domicilio de ésta y su madre, en la calle Galileo ${ }^{\circ} 45$ de Madrid. La Liga publicaba la revista Sexus en la que escribían los médicos más eminentes del momento.

En su artículo titulado «La Virgen Roja» publicado en la revista The Adelphi en junio de 1933, Havelock Ellis dice que mantenía correspondencia con Hildegart y que ella le escribía, en inglés, contándole sus actividades. Hildegart había nacido en 1914. Por lo tanto, en 1933, tenía apenas diecinueve años, y ya daba conferencias y escribía libros, folletos y artículos en periódicos como La Tierra, sobre eugenesia, educación sexual, etc. Militó primero en el Partido Socialista y después se unió a los republicanos federalistas. Sabía varios idiomas, había estudiado filosofía, medicina y se había licenciado en derecho. Dice además Ellis:

«Las últimas actividades de Hildegart se relacionan con la Liga Mundial para la Reforma Sexual. Con una inmensa energía y una rapidez que hubiera parecido extraordinaria en la vieja España, en pocas semanas consiguió crear la rama española de la Liga Mundial para la Reforma Sexual con el Dr. Marañón como presidente y ella misma como secretaria, junto con el apoyo de un amplio número de distinguidos médicos y políticos, mientras que ha sido capaz de producir y publicar una excelente revista dedicada a los asuntos del sexo, la primera en España»22.

Escalante, que escribe su libro en plena República, se manifiesta partidario del divorcio, considera que las relaciones sexuales no tienen por qué tener como único fin la procreación y piensa que la mujer tiene derecho al placer sexual y a ser un sujeto activo en las relaciones. $\mathrm{Y}$ alaba las nuevas medidas legislativas que permiten el divorcio, que eliminan como delito la homosexualidad aunque la considere una enfermedad. En fin, posiciones avanzadas que rompían con los

21 Puede verse esta historia, de gran repercusión en Madrid en los años treinta, en Álvarez PeláEZ, Raquel y HuERTAS GARCíA-AlEjO, Rafael: ¿Criminales o locos? Dos peritajes psiquiátricos del Dr. Gonzalo R. Lafora, Madrid, C.S.I.C. (Cuadernos Galileo de Historia de la Ciencia 6), 1987, pp. 57-200.

22 Ibid., Apéndice III, pp. 325-331. 
estereotipos. Escalante demuestra conocer el tema sobre el que ha escrito, las obras de otros y perfectamente la situación del momento. Pero, como lo hemos señalado antes, hay aspectos de la obra que hacen sospechar que sus intenciones iban más allá de ofrecer la divulgación de los diversos aspectos de la sexualidad.

\section{MARTÍN DE LUCENAY, «DOCTOR EN SEXOLOGÍA»}

Martín de Lucenay, autoproclamado «sexólogo» y citado por sus colegas escritores de obras sobre el sexo, tuvo una amplia producción de escritos, concretamente una colección de sesenta volúmenes titulada Temas sexuales. Biblioteca de divulgación sexual que comprendía, como es obvio, todo tipo de temas: $E l$ matrimonio de prueba, Causas sexuales del divorcio, La prostitución, La trata de blancas - dice también que es «Ex agregado en las misiones de Lucha contra la trata de blancas en Sudamérica y Tráfico de estupefacientes en Extremo Oriente»-, Un mes entre prostitutas, Los males venéreos, Esterilidad e impotencia, Las perversiones sexuales, Masturbación y autoerotismo, Homosexualidad, etc.

Lucenay es un buen escritor, conciso y sin retóricas, y su forma de hacer da una imagen de ser un individuo inteligente. Conoce los temas de los que habla, la bibliografía más al uso sobre ellos y sabe transmitir los conocimientos y hacer reflexiones muchas veces interesantes, que van más allá de los tópicos.

Por ejemplo, en el volumen en que se refiere a la eugenesia, La selección sexual $^{23}$, manifiesta conocer perfectamente los orígenes de la teoría eugénica, sus puntos esenciales, su desarrollo fuera y dentro de España. Considera que la eugenesia es un conjunto de higiene psíquica y física y que es para los eugenistas alemanes para quienes la eugenesia sería la higiene de las «disposiciones hereditarias contenidas en las células de la reproducción». Hace una larga historia de las actitudes eugénicas - como era frecuente en los libros de la época- desde los griegos hasta Galton, y habla de los eugenistas contemporáneos más conocidos, como el brasileño Renato Kehl, que, dice, promovió una nueva orientación médico social. Se refiere también, como Escalante, al Curso eugénico de 1928 y su suspensión por la autoridad y hace una alabanza a Marañón, «iniciador y alentador de la grandiosa cruzada contra el tartufismo, la incultura y la hipocresía». También conoce la Liga Española para la Reforma Sexual, y se refiere a los temas candentes de las propuestas eugénicas que se encontraban en debate: el control de natalidad y el certificado médico prenupcial.

Lucenay estaba, pues, perfectamente al tanto de todos los movimientos españoles y de las actividades de sus protagonistas. Es interesante su posición con

23 MARTín de LuCEnAy, A.: La Selección Sexual. La Eugenesia - La teoría y la práctica - Causas de la degeneración de la raza - La mujer y la selección - Paternidad legítima y la selección - Paternidad legítima $y$ sexualidad incestuosa - El crisol de la raza, Madrid, Editorial Fénix (Temas sexuales. Biblioteca de divulgación sexual, $\left.\mathrm{n}^{\circ} 20\right), 1933,95 \mathrm{p}$.

Hispania, LXIV/3, núm. 218 (2004) 947-960 
respecto a la importancia del determinismo de la herencia, pues dice que duda de que las leyes de la herencia sean, "hoy por hoy, las bases de una ciencia exacta». Y añade que "una cosa es fundar los hechos en la herencia y otra deducir de los hechos los antecedentes que quieren suponerse hereditarios y causantes de dichos estragos». Era, pues, un autor bien documentado, que conocía perfectamente los temas de los que hablaba, muchas veces mejor y con reflexiones más sensatas que muchos de los sesudos médicos y abogados del momento. Sin embargo, no se priva, en su momento, de introducir láminas de mujeres desnudas, en general exóticas, como sucedía en otras obras de características similares.

Por lo tanto, había una serie de escritores conocedores de todos los aspectos de la sexualidad que aprovechaban, en cierta medida, tales conocimientos no sólo para hacer una divulgación indudablemente necesaria, sino para, avanzado un paso, agregar elementos atractivos que hicieran más vendibles sus libros, como detalladas historias de relaciones sexuales extrañas o perversas, como en el libro de Martín de Lucenay publicado dentro de la misma serie «Temas sexuales», La sexualidad maldita, y láminas representado mujeres desnudas, a veces como ejemplos de la belleza de las diferentes razas, otras como ejemplos exóticos o representaciones de situaciones sexuales «perversas».

\section{LA FLAGELACIÓN ERóTICA DE ANTONIO SAN DE VELILLA}

Uno de los libros más llamativos en este aspecto el del Dr. Antonio San de Velilla titulado La flagelación erótica ${ }^{24}$. El título completo, como podemos comprobar en la nota a pie de página, es toda una exposición abreviada del contenido, una forma de presentación que era habitual en este tipo de libros. Una manera más de atraer de forma rápida y directa a los posibles lectores. En otros casos, como veremos, el reclamo era el dibujo de la cubierta.

En esta obra, el autor comienza hablando sobre las «perversiones del instinto genital, caracterizadas todas ellas por un deseo morboso de acentuar el placer causando o recibiendo dolor». Dice que nunca se habían publicado tantos libros «en que se historia o se estudia la frecuencia y el arraigo de la flagelación en los distintos países». Y señala que Ellis piensa que el látigo ha representado mucho en nuestra civilización. No sólo como perversión, sino como frecuente y común castigo. Intenta el autor analizar el por qué el dolor pueda causar placer

24 SAN de Velilla, Antonio: La flagelación erótica. En las escuelas, en los conventos y casas de corrección; en las cárceles y en los presidios; en la alcoba conyugal, en las mancebias, etc, etc. Estudio de psicopatía sexual, basado en los más modernos trabajos científicos sobre el masoquismo y el sadismo, avalorado con la exposición y análisis de gran número de casos observados en la clínica o entresacados de obras famosas en las que se analizan las causas de la relación frecuente entre el amor y el dolor, Compilación, notas y glosas del Dr. --, Edición ilustrada, Barcelona, Carlos Ameller Editor, 1932, 249 p.

Hispania, LXIV/3, núm. 218 (2004) 947-960 
y toma relatos de «atrocidades sexuales» contadas por nuestro conocido Martín de Lucenay y sucedidas en tierras lejanas como China, África, etc.

También habla del masoquismo y del sadismo, utilizando las opiniones de Krafft-Ebing, el más citado en todos los libros de este tipo, así como los escritos de Rousseau y sus Confesiones. Incluye en este libro abundancia de historias sobre sado-masoquismo y un apartado especial a la flagelación. Transcribe párrafos de Flageladores y flagelados, un librillo suyo que después comentaremos, de La sexualidad maldita de Lucenay, etc. La obra contiene alrededor de cuarenta ilustraciones, grabados ingleses, alemanes, españoles, representando actitudes sádicas, flagelaciones varias, tomadas de obras diversas (Esclavas modernas, Flagellantes et Flagellées, etc.), así como ejemplos de flagelación religiosa y en los colegios. Incluye la obra también una abundante bibliografía sobre, fundamentalmente, la flagelación.

San de Velilla tenía también en pequeño formato un libro de setenta páginas titulado, en el exterior, La mujer flageladora. La inversión sexual y la flagelación, dentro de una serie titulada «El consejero del matrimonio». Como siempre, aparece también en la cubierta el índice, debajo de un dibujo en colores que representa una mujer flagelando a otra, ambas prácticamente desnudas, imagen que debía ser tremendamente escandalosa. Lo curioso es que en la portada interior la obra se llama Pasiones infames (Flageladores y flagelados) ${ }^{25}$, y aquí sí que se encuentra el nombre del autor, San de Velilla, y además se repite el índice del contenido:

«De lo grotesco a lo trágico - La sodomía y las leyes - La bestialidad - Pigmalionismo - El amor y la muerte - La violencia como recurso amoroso - El matrimonio por rapto - La flagelación y la emoción sexual - La inversión sexual y la flagelación - La mujer flageladora - Flagelación venal - La flagelación entre casados - El látigo en el hogar y en la escuela (padres y maestros sádicos) - La flagelación en los conventos».

Este índice nos indica un contenido semejante a la obra del mismo autor antes citada, pero resumido y dedicado, en realidad, a contar historias escabrosas. En el caso de este pequeño libro, que costaba una peseta, no contenía ilustraciones interiores. En la contratapa, encontramos unas curiosas citas de revistas o autores extranjeros, una «Justificación de este nueva Biblioteca de Educación Sexual», citando, por ejemplo, un párrafo del British Medical Journal, de 1894 , en defensa de la educación sexual.

25 SAN DE VeliLla, Antonio: Pasiones infames (Flageladores y flagelados), Barcelona, Biblioteca de Educación sexual, s.f., 70 p.

Hispania, LXIV/3, núm. 218 (2004) 947-960 


\section{LA HOMOSEXUALIDAD FEMENINA SEGÚN OCTAVIO PLADEUR}

Esa misma justificación también aparecía, exactamente igual, en otro librito, casi folleto, del mismo tipo que el anterior aunque un poco más pequeño, dentro de la «Guía íntima del matrimonio (Manualitos de educación sexual)», del Doctor Octavio Pladeur y titulado Las mujeres lesbianas (Mujeres-hombres y matrimonios de mujeres) ${ }^{26}$. En este casi folleto, el autor de origen francés se dedica a describir todo tipo de relaciones lésbicas, admitiendo que la pasión y el amor pueden ser iguales a la pasión y el amor heterosexuales.

En este aspecto, es curioso reconocer que en muchas de estas obras había posiciones más adelantadas y mayor conocimiento y comprensión que la manifestada en otras obras más «serias», aunque bien es verdad que en ese tipo de libros no se hablaba, puede decirse que nunca, de las llamadas perversiones sexuales. Y cuando así se hacía era desde un punto de vista "científico», explicaciones de la considerada - por todos- enfermedad y sus posibles mecanismos. Pero, en general, los médicos se preocupaban más de la educación sexual en relación con el matrimonio, sin considerar las otras posibilidades, que, quizás por la importancia que tenía la sexualidad dentro del matrimonio, y por las presiones sociales y religiosas que hacían que no fuera adecuado referirse a esas perversiones, se abstenían de tratarlas.

Sólo hemos encontrado algunos pocos trabajos sobre la homosexualidad, siempre en tono circunspecto, por ejemplo en las obras de Marañón, intentando explicar su causa dentro de su teoría de la intersexualidad y los procesos endocrinológicos, o en las publicaciones del médico catalán Félix Martí Ibáñez, psiquiatra anarquista que tenía, en la revista Estudios, el «Consultorio Psíquico-sexual»27.

El librito o folleto a que nos referíamos más arriba se compone sólo de tres capítulos. En ellos vemos relatados todos los detalles de las relaciones lésbicas, así como la clasificación de lesbianas entre «innatas» y "formadas». O sea, que se consideraba que algunas mujeres nacían «así» y otras eran inducidas, como sucedía en la homosexualidad masculina: había quienes tenían la «enfermedad» y quienes eran deformados por otros.

Vamos a ofrecer los títulos de cada capítulo porque son claramente demostrativos del contenido del libro de Pladeur. El primer capítulo trata así de «El amor más refinado - Lo que es el amor lesbio - La pasión inverosímil de las hijas de Safo - La lesbiana innata y la formada - Cómo nace el lesbianismo». El segundo capítulo comprende: «Matrimonios de mujeres - El marido y la mujer en las relaciones lesbianas - El exhibicionismo y el lenguaje de las lesbianas Las safistas de París y sus extravagancias - Más casos terribles de amor lésbi-

26 Pladeur, Dr. Octavio: Las mujeres lesbianas (Mujeres-hombres y matrimonios de mujeres), Versión española de Patricio MARzo, Barcelona, Guía íntima del matrimonio (Manualitos de educación sexual), Primera serie, Núm. 10, s.f.

27 MARTí IBÁÑEZ, Félix: «Consideraciones sobre el homosexualismo», Estudios (Valencia), n 145 (1935), pp 3-5. 
co». Y el tercer capítulo contiene los apartados siguientes: «Las lesbianas de París - Casos terribles de amor lesbio - Perversión y aberración femenina - Las lesbianas de la clase baja y las del mundo elegante - El menage-à-trois [sic] entre mujeres».

El opúsculo se compone, en realidad, de relatos de relaciones varias entre mujeres, de historias, aderezado todo, para los españoles, con el hecho de que esas historias se situaban en París. Al final del opúsculo, el autor relata la relación ardiente entre tres mujeres. Y el último párrafo dice:

\footnotetext{
«Y aquellas tres mujeres salieron luego juntas, y como tres burguesitas decentes y honradas, subieron al auto que las esperaba y marcharon hacia los bulevares del centro de París».
}

Había, pues, en la España de los años veinte y treinta del siglo XX, una abundante literatura seria, sesuda, preocupada por la situación española en cuanto a la educación sexual, la mortalidad infantil de la que era responsable, en cierta medida, la ignorancia que existía con respecto al sexo, los conflictos morales y prácticos en las relaciones sexuales entre los miembros del matrimonio y en las relaciones extramatrimoniales. Pero también, como es lógico, una literatura que va desde una apariencia de querer divulgar los conocimientos sobre la sexualidad hasta la casi abierta pornografía, como creo haber mostrado con los ejemplos presentados más arriba.

Quizás este tipo de libros, que respondían a la enorme avidez que existía en España por adquirir conocimientos sobre la vida sexual, que se demostraba en que todo tipo de conferencia, charla, curso que se diera sobre este tema, atrayendo grandes cantidades de público de todo tipo, fuera en muchos casos más útil para la gente corriente, no perteneciente a las clases medias privilegiadas, que otras publicaciones. Recordemos nuevamente que el Curso Eugénico de 1928, propiciado por la Facultad de Medicina, estaba abarrotado de gente. Y éste fue el argumento esgrimido por la Iglesia y su periódico $E l$ Debate, pues las ideas que se transmitían en el Curso debían discutirse sólo entre profesionales, para que no se diera lugar al «regodeo pornográfico» ${ }^{28}$.

Para universitarios y clases medias, un libro clave fue Amor, conveniencia $y$ eugenesia, de Gregorio Marañón, libro que planteaba los problemas de elegir pareja y la necesidad de una elección adecuada de pareja para tener una buena y sana progenie. Pero no se hablaba en ella de sexualidad, sino, en realidad, aunque no de forma explícita, de sublimar la sexualidad, que parecía sólo dedicada a la procreación. En efecto, en estos libros de profesionales reconocidos, no se hablaba realmente de sexo. Por lo tanto, es posible que esos ambiguos libros que hemos presentado cumplieran alguna función útil y no sólo la del «regodeo pornográfico».

\footnotetext{
28 ÁlvAREZ, Raquel: «Origen y desarrollo de la eugenesia en España», op. cit.
} 